\title{
Long acting injectable naltrexone is effective and safe for treating alcohol dependence
}

Garbutt JC, Kranzler HR, O'Malley SS, et al. Efficacy and tolerability of long-acting injectable naltrexone for alcohol dependence: a randomized controlled trial. JAMA 2005;293:1617-25.

\section{Is long acting injectable naltrexone an effective and safe treatment for adults with alcohol dependence?}

\section{METHODS}

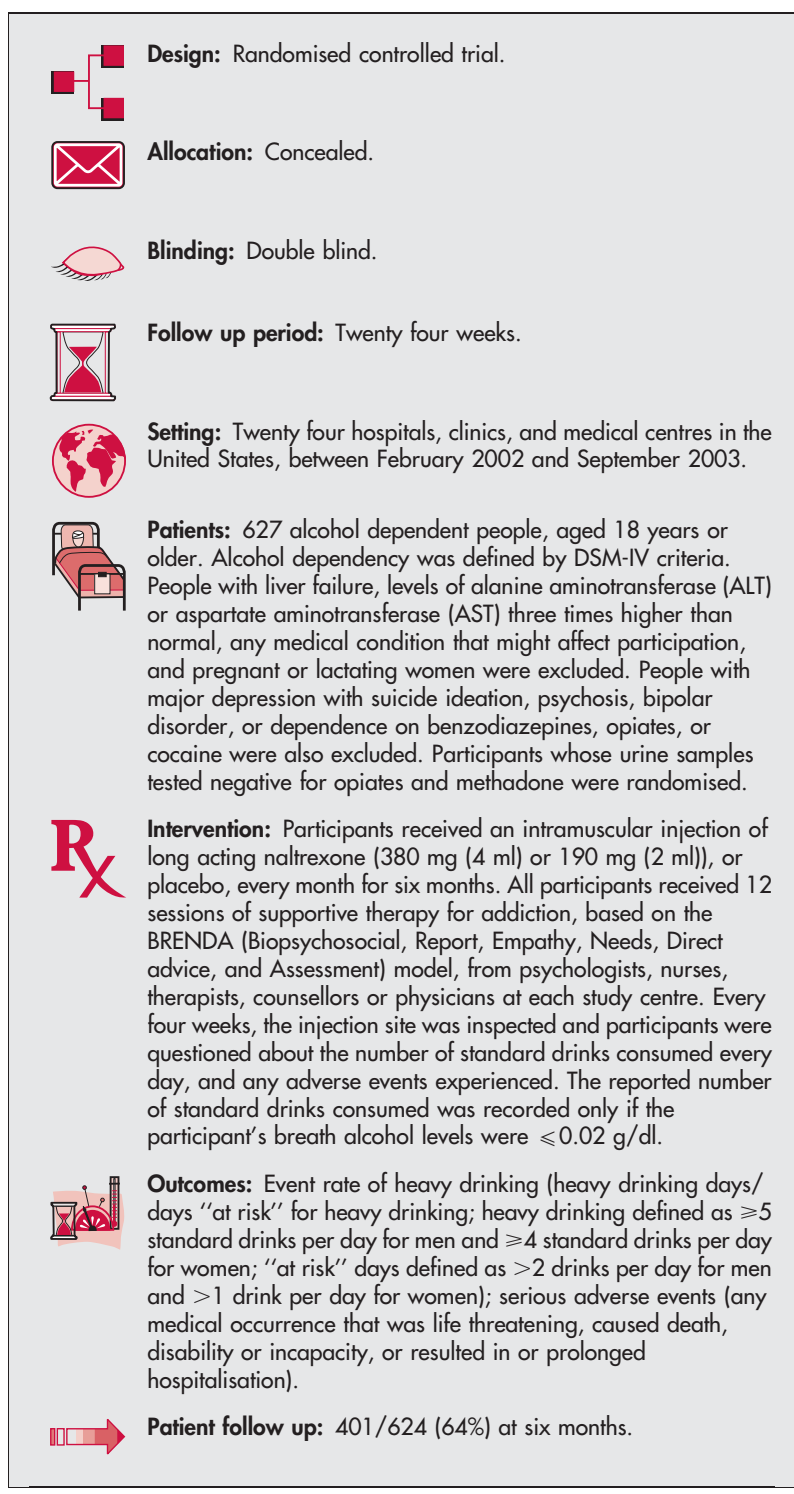

\section{MAIN RESULTS}

Long acting, higher dose injectable naltrexone $(380 \mathrm{mg})$, but not lower dose $(190 \mathrm{mg})$, significantly reduced heavy drinking compared with placebo at six months (380 mg: HR $0.75,95 \%$ CI 0.60 to 0.94 ;

For correspondence: James $C$ Garbutt, $M D, C B$ CB No 7160 University of North Carolina at Chapel Hill, Chapel Hill, NC 27599-7160, USA; ic_garbutt@ med.unc.edu

Sources of funding: Alkermes Inc, and grants from the National Institutes of Health and the National Institute on Alcohol Abuse and Alcoholism.
$190 \mathrm{mg}$ : HR $0.83,95 \%$ CI 0.68 to 1.02$)$. There was a similar rate of serious adverse events between treatments (11/205 (5.4\%) with $380 \mathrm{mg} v 10 / 210(4.8 \%)$ with $190 \mathrm{mg} v$ 15/209 (7.2\%) with placebo; $\mathrm{p}$ value not reported).

\section{CONCLUSIONS}

Long acting injectable naltrexone reduced heavy drinking compared with placebo in alcohol dependent adults. There was a similar rate of serious adverse events with naltrexone and placebo.

\section{Commentory}

The efficacy of naltrexone, an opiate antagonist, in reducing relapse to heavy drinking in people with alcohol dependence has been demonstrated in numerous studies. For people who are most adherent to the prescribed medication the efficacy is more robust. However, in studies performed in frontline treatment programmes with more heterogeneous populations and with fewer exclusion criteria, adherence to the medication regimen has been less than optimal. Adherence is therefore an important factor in determining the feasibility of naltrexone in clinical practice. ${ }^{1-3}$

The development of a long acting injectable naltrexone to address this problem shows promise. The safety profile and tolerability of the injectable naltrexone, Vivitrex, has been established and is comparable, if not better, than oral administration. ${ }^{4}$ In this large, six month multisite trial by Garbutt et al, monthly administration of Vivitrex reduced heavy drinking episodes in people with alcohol dependence. Retention was high, suggesting the injectable route of administration was acceptable to patients. The $380 \mathrm{mg}$ dose was significantly better than placebo $(p<0.03)$, while the $190 \mathrm{mg}$ dose approached significant difference from placebo $(p<0.07)$.

Clinicians should be aware that certain subgroups of patients might be more or less responsive to the medication. This study showed that being male and abstinent seven days before receiving the first injection were factors that contributed to better outcomes. Although naltrexone was administered in combination with a 12 session low intensity psychosocial therapy, the most improved outcomes are associated with combination cognitive behavioural therapy. ${ }^{6}{ }^{6}$ However, naltrexone combined with several different psychosocial therapies can reduce relapse to heavy drinking and recidivism in this treatment resistant population. As such, there is a clear indication to integrate this treatment into clinical practice, particularly for alcohol dependent men and those who are not actively using at the initiation of treatment.

Therese K Killeen PhD APRN BC Medical University of South Carolina, Charleston, SC, USA

1 Volpicelli JR, Rhines KC, Rhines JS, ef al. Naltrexone and alcohol dependence: role of subject compliance. Arch Gen Psychiatry 1997; $54: 737-42$

2 Chick J, Anton R, Checinski K, et al. A multicentre, randomized, doubleblind, placebo-controlled trial of naltrexone in the treatment of alcohol dependence or abuse. Alcohol Alcohol 2000;35:587-93.

3 Killeen TK, Brady KT, Gold PG, et al. Effectiveness of naltrexone in a community treatment program. Alcohol Clin Exp Res 2004;28:1710-17.

4 Johnson BA, Ait-Daoud N, Aubin HJ, et al. A pilot evaluation of the safety and tolerability of repeat doseadministration of long-acting injectable Naltrexonr (Vivitrex) in patients with alcohol dependence. Alcohol Clin Exp Res 2004;28:1356-61.

5 O'Malley SS, Jaffe AJ, Chang G, et al. Naltrexone and coping skills therapy for alcohol dependence. A controlled study. Arch Gen Psychiatry 1992;49:881-7.

6 Balldin J, Berglund M, Borg S, et al. A 6-month controlled naltrexone study: combined effect with cognitive behavioral therapy in outpatient treatment of alcohol dependence. Alcohol Clin Exp Res 2003;27:1142-9. 